\title{
TREATMENT OF THE HAMMAN-RICH SYNDROME WITH CORTISONE
}

\author{
BY \\ JOHN READ AND R. A. B. HOLLAND \\ From the Department of Medicine, University of Sydney, and the Thoracic Unit, \\ Royal Prince Alfred Hospital, Sydney
}

(RECEIVED FOR PUBLICATION MARCH 31, 1958)

The syndrome of diffuse interstitial pulmonary fibrosis of unknown aetiology was first described by Hamman and Rich $(1935,1944)$ as an acute illness leading to death from respiratory insufficiency or cor pulmonale within six months of the onset of symptoms. This concept of its acute and fatal nature persisted for several years, but a number of cases have now been reported, similar to the original group of Hamman and Rich, except that they have survived for periods of many years. Scadding (1956) has indeed reported a group of patients with diffuse interstitial fibrosis of the lungs whose symptoms are almost static; and for this and other reasons he considers that the eponym "Hamman-Rich" should not be applied to them. Despite this modification of the overall prognosis, the outlook remains grave.

The aetiology of the condition has been described as obscure, and numerous hypotheses have been advanced concerning it. Tissue hypersensitivity was first suggested as a cause by Peabody, Peabody, Hayes, and Hayes (1950). The circumstantial evidence supporting such a thesis has been summarized by Read (1958a), who has also produced (Read, 1958b) experimental lesions in rats morphologically identical with those of the Hamman-Rich syndrome by the administration of rabbit anti-rat-lung serum.

The therapeutic use of corticotrophin and adrenal steroids has been reported by several writers. Patterns of response fall into three main groups :

(1) No effect or mild subjective benefit only (Cox and Kohl, 1952 ; Callahan, Sutherland, Fulton, and Kline, 1952; Rubin, Kahn, and Pecker, 1952 ; Silverman and Talbot, 1953); (2) benefit, subjective, objective, or both, followed by fatal relapse on cessation of therapy (Peabody, Buechner, and Anderson, 1953 ; Schechter, 1953); (3) objective remission, maintained by long-term administration of steroids (Pinney and Harris, 1956).
Detailed studies of respiratory function, and especially of change in function in response to treatment, are few in this condition. There have been many reports of cases showing cyanosis, reduction in lung volumes, reduced or normal maximum breathing capacity, terminal polycythaemia, and right ventricular hypertrophy. A few cases have been studied in more detail. Silverman and Talbot (1953) reported a case showing arterial oxygen unsaturation, raised cardiac output, and pulmonary hypertension. Cugell, Marks, Ellicott, Badger, and Gaensler (1956) reported a case with arterial oxygen unsaturation and lowered diffusing capacity on exercise, and with general reduction of lung volumes and maximum breathing capacity. The case of Merrill, Callaway, and Meneely (1956) showed decreased lung volumes and maximum breathing capacity, and a lowered arterial oxygen saturation at rest. It is possible that several of the cases of Baldwin, Cournand, and Richards (1949), of Marks, Cugell, Cadigan, and Gaensler (1957), and of Lépine, Laberge, Lapalme, Soucy, Borduas, and Grégoire (1957) fall into this category, but in the absence of more evidence they cannot be regarded as examples of the Hamman-Rich syndrome.

It is proposed to report the history of a patient whose case probably falls into the group described by Hamman and Rich. Although lung biopsy was not performed the diagnosis rests on very strong evidence. This patient showed an excellent response to adrenal steroids, demonstrated objectively by detailed pulmonary function studies. It seems possible that the condition was precipitated by sulphonamides.

\section{Case Report}

A married Italian woman, aged 39 years, had always been in excellent health. She was delivered of a healthy child by Caesarean section in October, 1956, and recalled that even when her pregnancy was 
advanced she had not been troubled by dyspnoea. In January, 1957, she developed a breast abscess which was drained under general anaesthesia, again without untoward effect. At this time she was given 10 daily intramuscular injections of penicillin and 14 days of sulphonamide therapy ( $4 \mathrm{~g}$. per day).

From about that time she began to notice increasing dyspnoea of effort. By March, 1957, she became readily breathless on climbing hills and stairs, and because of this was given four weeks' therapy with $4 \mathrm{~g}$. daily of a sulphonamide. Her dyspnoea worsened further and in April, 1957, she was referred to the Thoracic Unit of the Royal Prince Alfred Hospital. She had had very little cough.

On examination she did not look acutely ill. The respiratory rate was increased to between 30 and 40 per minute, and she had mild cyanosis of the lips and fingers. The fingers were clubbed. Chest movement was a little diminished on both sides, and fine crepitations could be heard over the whole of both lungs. No other abnormality could be detected in any system. A chest radiograph showed a fine generalized reticular mottling over the whole of both lung fields. This was so fine that no attempt can be made to reproduce it photographically.

She was admitted to hospital for detailed study. The temperature rose daily to $99^{\circ} \mathrm{F}$. Haemoglobin estimation and blood leucocyte counts gave results within normal limits. The erythrocyte sedimentation rate was slightly elevated. The Mantoux reaction was negative to 1:100 old tuberculin. Examination of mucoid sputum revealed no acid-fast bacilli, carcinoma cells, fungi, or consistent pathogens, though from one specimen Staph. aureus was cultured. The urine was normal on chemical and microscopic examination. There was no polycythaemia. No lupus erythematosus cells were demonstrated in the peripheral blood. Radiographs of the hands showed no sarcoid-like lesions. Electrophoretic separation of the serum protein constituents by Dr. B. G. Firkin showed: serum albumin 2.3 g., $\alpha_{2}$ globulin 1.4 g., $\beta$ globulin $1.9 \mathrm{~g}$., $\gamma$ globulin $2.2 \mathrm{~g}$. per $100 \mathrm{ml}$.; i.e., there was diminution in the albumin and increase in the gamma globulin fractions. An electrocardiogram was normal. Biopsy of the right scalene lymph node yielded normal lymphoid tissue.

Physiological studies of respiratory function were carried out on April 12, 1957, and twice subsequently. The methods used were largely those used by Holland and Blacket (1958) in their study of steady state diffusing capacity for carbon monoxide $\left(\mathrm{D}_{\mathrm{co}}\right)$. The diffusing capacity was determined by the method of Filley, MacIntosh, and Wright (1954) with minor modifications: carbon monoxide in inspired and expired air was measured with an infra-red gas analyser, and arterial $\mathrm{CO}_{2}$ tension by the HendersonHasselbalch equation. Blood gases were estimated by the manometric methods of Van Slyke and Neill (1924) and $p \mathrm{H}$ of whole blood was measured with a Stadie micro-electrode in an anaerobic cell using a Cambridge $p \mathrm{H}$ meter. Lung volumes were determined on a 6-litre Knipping spirometer, the functional residual capacity being measured by the closed-circuit helium technique, modified from the method of McMichael (1939). Maximum voluntary ventilation (M.V.V.) was determined over 12 seconds' breathing in the closed circuit. The values of lung volumes and M.V.V. have been compared with the values predicted for the patient by the formulae of Needham, Rogan, and McDonald (1954). Evenness of intrapulmonary gas mixing was assessed by the closed-circuit helium technique (Read, 1958c). Resting studies were performed sitting up, and exercise consisted of a steptest, five minutes being allowed for a steady state to be reached.

The results of these studies are shown in Tables I and II.

Before treatment the patient showed marked reduction in all lung volumes. No component was specifically affected, but the residual volume/total lung capacity (R.V./T.L.C.) ratio was raised because of the relatively smaller reduction in the residual volume. The M.V.V. was also reduced. There was resting arterial oxygen unsaturation, raised blood $p \mathrm{H}$, and low arterial $\mathrm{CO}_{2}$ tension. The $\mathrm{D}_{\text {co }}$ was $4.2 \mathrm{ml}$./ $\mathrm{min} . / \mathrm{mm}$. $\mathrm{Hg}$ (normal mean in this laboratory $22 \mathrm{ml}$./ $\mathrm{min} . / \mathrm{mm}$. $\mathrm{Hg}$ ). A small defect in intrapulmonary mixing was demonstrated. The physiological dead space/tidal volume ratio (after correcting dead space for that of the mouthpiece) was a little raised. The patient was too disabled for studies to be performed during exercise.

Because of the severe incapacity revealed by clinical and physiological observations, thoracotomy and lung biopsy were not considered justified. With a presumptive diagnosis of acute diffuse interstitial fibrosis (Hamman-Rich syndrome) cortisone therapy was begun, with $300 \mathrm{mg}$. on the first day, $200 \mathrm{mg}$. on the second day, and $100 \mathrm{mg}$. daily thereafter. Chloramphenicol, $1 \mathrm{~g}$. daily, was also given because of the isolated finding of staphylococci in the sputum. Improvement was dramatic. Exercise tolerance improved and all abnormal signs in the chest disappeared within a few days. The radiographic appearances were much improved within 10 days, and were regarded as within normal limits by the end of three weeks.

Physiological studies were repeated on May 3, 1957 , after 10 days' treatment with cortisone (Tables I and II). These showed improvement in every respect. There had been a distinct increase in the total lung capacity due to an improved vital capacity. The M.B.C. and intrapulmonary gas mixing were now normal. The dead space/tidal volume ratio had fallen to normal limits. Arterial oxygen saturation was normal at rest and remained so on exercise (which, though not severe, exhausted the patient). Blood $\mathrm{CO}_{2}$ tension was still low ăt rest. The $\mathbf{D}_{\text {co }}$ had more than doubled since the previous estimation. It showed a good rise on exercise, though figures were still below normal.

After these studies, chloramphenicol was withdrawn and the dosage of cortisone steadily reduced. Clinical improvement was maintained, and the patient was 
TABLE I

LUNG VOLUMES AND MAXIMUM BREATHING CAPACITY BEFORE AND AFTER TREATMENT*

\begin{tabular}{|c|c|c|c|c|c|c|c|c|c|}
\hline \multirow[b]{2}{*}{ Date } & \multicolumn{2}{|c|}{ Vital Capacity } & \multicolumn{2}{|c|}{ Total Lung Capacity } & \multicolumn{2}{|c|}{ Residual Volume } & \multirow{2}{*}{$\begin{array}{c}\text { Residual Volume/ } \\
\text { Total Lung } \\
\text { Capacity }\end{array}$} & \multicolumn{2}{|c|}{ M.V.V. } \\
\hline & Litres & Predicted & Litres & Predicted & Litres & Predicted & & $1 . / \mathrm{min}$ & $\begin{array}{c}\% \\
\text { Predicted }\end{array}$ \\
\hline $\begin{array}{r:rl}12 & 4 & 57 \\
3 & 5 & 57 \\
19 & 11 & 57\end{array}$ & $\begin{array}{l}1 \cdot 39 \\
2 \cdot 23 \\
2 \cdot 33\end{array}$ & $\begin{array}{r}57 \\
91 \\
100\end{array}$ & $\begin{array}{l}2 \cdot 30 \\
3 \cdot 01 \\
3 \cdot 14\end{array}$ & $\begin{array}{l}58 \\
76 \\
82\end{array}$ & $\begin{array}{l}0.83 \\
0.76 \\
0.75\end{array}$ & $\begin{array}{l}54 \\
49 \\
48\end{array}$ & $\begin{array}{l}0.36 \\
0.25 \\
0.24\end{array}$ & $\begin{array}{l}51 \\
77 \\
77\end{array}$ & $\begin{array}{l}59 \\
90 \\
91\end{array}$ \\
\hline
\end{tabular}

* Patient was well below average size; body surface area $=1.43 \mathrm{sq} . \mathrm{m}$.

TABLE II

BLOOD GASES, RESPIRATORY EXCHANGE RATIO, DEAD SPACE VALUES, AND DIFFUSING CAPACITY BEFORE AND AFTER TREATMENT

\begin{tabular}{|c|c|c|c|c|c|c|c|c|c|}
\hline Date & $\begin{array}{l}\text { Rest or } \\
\text { Exercise }\end{array}$ & $\begin{array}{c}\text { Oxygen } \\
\text { Consump- } \\
\text { tion } \\
\text { (ml./min.) }\end{array}$ & $\begin{array}{c}\text { Arterial } \\
\text { Oxygen } \\
\text { Saturation } \\
(\%)\end{array}$ & $\begin{array}{c}\text { Whole } \\
\text { Blood } \\
p \mathrm{H}\end{array}$ & $\begin{array}{c}\text { Arterial } \\
\mathrm{CO}_{2} \\
\text { Tension } \\
\text { (mm. } \mathrm{Hg})\end{array}$ & $\begin{array}{c}\text { Respiratory } \\
\text { Exchange } \\
\text { Ratio }\end{array}$ & $\begin{array}{l}\text { Dead } \\
\text { Space* } \\
\text { (ml.) }\end{array}$ & $\begin{array}{c}\text { Dead } \\
\text { Space } \\
\text { Tidal } \\
\text { Volume* } \\
(1 .)\end{array}$ & $\begin{array}{c}\text { Diffusing } \\
\text { Capacity } \\
\text { for } \mathrm{CO} \\
\text { (ml. } \mathrm{min} . \\
\mathrm{mm} . \mathrm{Hg})\end{array}$ \\
\hline $\begin{array}{rl:l}12 & 4 & 57 \\
3 & 5 & 57 \dagger \\
& & \\
19 & 11 & 57 \dagger\end{array}$ & $\begin{array}{l}\text { Rest } \\
\text { Ë, } \\
\text { Rercise } \\
\text { Exercise }\end{array}$ & $\begin{array}{l}206 \\
225 \\
889 \\
194 \\
759\end{array}$ & $\begin{array}{l}84 \cdot 0 \\
95 \cdot 7 \\
95 \cdot 8 \\
95 \cdot 0 \\
94 \cdot 0\end{array}$ & $\begin{array}{l}7 \cdot 47 \\
7 \cdot 49 \\
7 \cdot 36 \\
7 \cdot 43 \\
7 \cdot 39\end{array}$ & $\begin{array}{l}33 \cdot 7 \\
34 \cdot 9 \\
36 \cdot 7 \\
36 \cdot 5 \\
37 \cdot 2\end{array}$ & $\begin{array}{l}0.85 \\
0.97 \\
1.11 \\
0.88 \\
0.96\end{array}$ & $\begin{array}{l}137 \\
107 \\
168 \\
101 \\
183\end{array}$ & $\begin{array}{l}0.35 \\
0 \cdot 30 \\
0 \cdot 19 \\
0 \cdot 34 \\
0 \cdot 21\end{array}$ & $\begin{array}{r}4 \cdot 2 \\
9 \cdot 8 \\
15 \cdot 0 \\
9 \cdot 4 \\
13 \cdot 9\end{array}$ \\
\hline
\end{tabular}

* Dead space corrected for dead space of mouthpiece. † Mean of two closely agreeing duplicates.

discharged from hospital in June, 1957, receiving $37.5 \mathrm{mg}$. of cortisone daily. She has continued this dosage to the time of writing (a total of 17 months) and has been reviewed regularly. Her general health remains excellent, and the chest radiograph has shown no further abnormal shadows. She has experienced no further dyspnoea. On several occasions fine crepitations have been heard over localized areas of the chest, but have disappeared without change in therapy. Finger clubbing has completely disappeared. Recent re-study of her serum proteins shows no essential change from the earlier abnormal pattern.

Further pulmonary function studies were carried out on November 19, 1957 (Tables I and II). Lung volumes and M.V.V. were the same as in May, 1957, but she performed the M.V.V. at a slower rate of breathing. Arterial blood gases and the $\mathbf{D}_{\text {co }}$ at rest and on exercise were unaltered when one allows for the slightly lighter exercise performed on this occasion. Again, the electrocardiogram was normal and there was no polycythaemia.

\section{Discussion}

Though no lung biopsy has been performed, this case is presented with some confidence as an example of the Hamman-Rich syndrome. Features supporting this diagnosis include: (i) the acute onset and progression of respiratory disability; (ii) the rapid development of finger clubbing; (iii) the presence of fine crepitations over all areas of the chest; (iv) the nature of the radiological changes; (v) the physiological disability which was similar to that in several proven cases of the Hamman-Rich syndrome (Holland, Harvey, Blacket, and Harvey, 1958).

A brief discussion of the differential diagnosis seems justified to defend this contention.

Sarcoidosis was the other diagnosis most seriously considered. There was no enlargement of lymph nodes-either superficial or at the hila of the lungs-nor of the spleen. Skin, eye, and bone lesions were absent. But pulmonary sarcoidosis with none of these accompanying features is common. Diffuse pulmonary infiltration accompanied by a rise of serum $\gamma$ globulin at least suggests sarcoidosis. Features which led to the rejection of this diagnosis included the rapid development of clubbing of the fingers, the presence of widespread crepitations all over the chest, the negative scalene node biopsy, and the nature of the radiological changes (linear rather than nodular). A combination of all these features is in our experience unknown in pulmonary sarcoidosis of recent onset.

There was no collateral evidence for a diagnosis of eosinophilic granuloma. There was no sign of diabetes insipidus or of bony lesions, and the rapid response to cortisone would not be expected in this condition.

Carcinomatosis and pulmonary adenomatosis are excluded by the subsequent course of the illness, as are congenital or acquired lesions of the honeycomb lung variety. There was no exposure to suggest berylliosis or one of the pneumonoconioses, or a radiation fibrosis. 
Continued well-being under the influence of cortisone alone would make infective conditions including miliary tuberculosis unlikely, while the initial clinical picture was quite unlike any of the pulmonary infections.

No cardiac lesion to account for a state of chronic pulmonary oedema could be detected. An allergic vasculitis would be unlikely to be confined to the pulmonary vessels. Similarly there were none of the systemic stigmata of polyarteritis nodosa or of lupus erythematosus.

It is suggested that in the presence of the classical history, and physical and special findings, a diagnosis of diffuse interstitial pulmonary fibrosis is tenable without lung biopsy.

In view of the evidence (Read, 1958a) that some cases at least of the Hamman-Rich syndrome are based on immune mechanisms, the possible part played by sulphonamides in the present case is of interest, although no firm conclusions can be drawn.

The functional changes improved greatly under cortisone therapy. The most striking abnormality, arterial oxygen unsaturation, has disappeared entirely even on moderate exercise. Previously it had been regarded as too severe at rest to permit lung biopsy. The very low initial $\mathrm{D}_{\mathrm{co}}$ indicated that the unsaturation was due to alveolo-capillary block, although a small amount of venous admixture cannot be excluded. The diffusional difficulty is attributable to a thickening of the alveolar membrane which resolved under the influence of cortisone, rather than to loss of diffusing surface. The $D_{c o}$ after treatment was still below normal.

The low arterial $\mathrm{CO}_{2}$ tension found before treatment is a manifestation of hyperventilation. This probably resulted from reflex stimulation of the respiratory centre, either due to low oxygen tension in the chemoreceptors or due to sensitization of the nerve endings in the lungs. It occurred on the first occasion in the presence of a normal respiratory exchange ratio, whereas the low $\mathrm{CO}_{2}$ tension found soon after the beginning of treatment was associated with a high and variable respiratory exchange ratio. This suggests that in the latter case the patient was not breathing steadily. In the most recent investigation the arterial $p \mathrm{H}$ and $\mathrm{CO}_{2}$ tension were closer to normal. The lowering of arterial $\mathrm{CO}_{2}$ tension is not a constant finding in these patients (the case reported by Merrill and others, 1956, had arterial $\mathrm{CO}_{2}$ tensions in the high normal range).

The decrease of lung volumes before treatment is regarded as due to an inflammatory thickening of the alveolar walls. This would have its effect partly by occupying space within the chest, and partly by increasing the rigidity of the lung and making full expansion more difficult. This hypothesis is supported by the increase in the lung volumes which occurred under the influence of cortisone, an increase which remained remarkably constant six months later. The improvement in M.V.V. is probably due to the increase in lung volumes and decreased lung turgidity.

Although the dead space/tidal volume ratio was a little raised initially, absolute values of the dead space were not increased. There had thus been minimal development of regions where ventilation was in excess of perfusion. This is in line with pathological observations made in another case of the Hamman-Rich syndrome: namely, that, though at necropsy there was considerable focal emphysema, none was found in a lung biopsy specimen obtained some months before (shortly after the onset of the illness). The normal electrocardiogram and haematocrit are not surprising in view of the early stage at which the disease was investigated and treated.

The initial response to cortisone has thus been satisfactorily maintained for a period of nine months. Persistence of the abnormal serum protein pattern suggests that the underlying cause is still present, and that pulmonary manifestations have merely been suppressed. A hyperglobulinaemia has been reported in several other cases of the Hamman-Rich syndrome, but the response of the protein pattern to treatment has not been recorded. The most recent studies of lung function indicate that there is some residual pulmonary damage, which is, however, clinically and radiologically inapparent. Only the patient of Pinney and Harris (1956) seems to have made a more satisfactory response to adrenal steroid therapy, but in their case no detailed studies of pulmonary function have been performed. As $\stackrel{\circ}{I}$ assessed on purely clinical and radiological grounds, the present patient's response is equally impressive.

\section{SUMMARY}

A case of acute diffuse interstitial pulmonary fibrosis (Hamman-Rich syndrome) is reported. Hypersensitivity to sulphonamides may have played some part in the genesis of the condition. Cortisone produced a striking remission of $\stackrel{\mathcal{C}}{\rightarrow}$ symptoms and signs, and improvement in objective ${ }^{0}$ tests of respiratory function; and this remission has been maintained for some nine months by $\stackrel{\mathbb{\Omega}}{\overparen{D}}$ continued cortisone therapy. Some subclinical $\stackrel{\mathbb{Q}}{\mathbb{Q}}$ pulmonary damage and an abnormal serum protein pattern persist. 
We wish to thank Dr. H. M. Rennie (under whose care the patient was) for permission to report the case and for helpful advice and criticism. One of us (R. H.) was working as a Marion Clare Reddall Research Scholar and the work was aided by grants from the National Health and Medical Research Council and the Joint Coal Board.

\section{REFERENCES}

Baldwin, E. de F., Cournand, A., and Richards, D. W., Jr. (1949). Medicine (Baltimore), $28,1$.

Callahan, W. P., Sutherland, J. C., Fulton, J. K., and Kline, J. R. (1952). A.M.A. Arch. intern. Med., 9u, 468.

Cox, T. R., and Kohl, J. M. (1952). Amer. J. clin. Path., 22, 770.

Cugell, D. W., Marks, A., Ellicott, M. F., Badger, T. L., and Gaensler, E. A. (1956). Amer. Rev. Tuberc. 74, 317 .

Filley, G. F., MacIntosh, D. J., and Wright, G. W. (1954). J. clin. Invest., 33, 530.

Hamman, L., and Rich, A. R. (1935). Trans. Amer. clin. climat. Ass., 51,154. Quoted by Hamman and Rich (1944).
(1944). Bull. Johns Hopk. Hosp., 74, 177.
Holland, R. A. B., and Blacket, R. B. (1958). Aust. Ann. Med., 7, 192. Harvey, H. P. B., Blacket, R. B., and Harvey, W. C. B. (1958). Unpublished.

Lépine, C., Laberge, M. J., Lapalme, J., Soucy, R., Borduas, J. L., and Grégoire, F. (1957). Un. med. Can., 86, 144.

McMichael, J. (1939). Clin. Sci., 4, 167.

Marks, A., Cugell, D. W., Cadigan, J. B., and Gaensler, E. A. (1957). Amer. J. Med., 22, 51.

Merrill, J. M., Callaway, J.J., and Meneely, G. R. (1956). Sth. med. J. (Bgham, Ala.), 49, 997.

Needham, C. D., Rogan, M. C., and McDonald, I. (1954). Thorax, 9,313 .

Peabody, J. W., Buechner, H. A., and Anderson, A. E. (1953). A.M.A. Arch. intern. Med., 92, 806.

- Peabody, J. W., Jr., Hayes, E. W., and Hayes, E. W., Jr. (1950). Dis. Chest, 18, 330

Pinney, C. T., and Harris, H. W. (1956). Amer. J. Med., $20,308$.

Read, J. (1958a). Amer. Rev. Tuberc., 78, 353. (1958b). J. Path. Bact. In the press.

- (1958c). Aust. Ann. Med., 7, 179.

Rubin, E. H., Kahn, B. S., and Pecker, D. (1952). Ann. intern. Med., $36,827$.

Scadding, J. G. (1956). Brit. J. Radiol., 29, 633.

Schechter, M. M. (1953). Amer. Rev. Tuberc., 68, 603.

Silverman, J. J., and Talbot, T. J. (1953). Ann. intern. Met., 38, 1326.

Van Slyke. D. D., and Neill, J. M. (1921). J. bio!. Chem., 61, 523. 